\title{
CONDICIONANTES dA FORMAÇÃo PROfissional do SERVIÇO SOCIAL PARA A PESQUISA: UMA APROXIMAÇÃo DE INSTITUIÇõeS PRIVAdAS
}

\author{
PROFESSIONAL GRADUATION CONDITIONS OF SOCIAL WORK TO \\ RESEARCH: AN APROACH TO PRIVATE INSTITUTIONS
}

Maria Lucia Garcia Mira ${ }^{1}$

\begin{abstract}
RESUMO
Este estudo decorre da pesquisa realizada junto a instituições de ensino privadas do município de São Paulo, que ofertam Cursos de Serviço Social, objetivando compreender como ocorria a formação para a pesquisa. Esta se constitui em um importante instrumento para a aproximação sistematizada da realidade pelos assistentes sociais. O estudo possibilitou o encontro da legislação e de referenciais que regulam a formação, a observação das condições institucionais, das condições do trabalho docente e de coordenadores de curso, bem como, as condições dos estudantes nesse processo.
\end{abstract}

PALAVRAS-CHAVE: Pesquisa. Formação Profissional. Serviço Social.

\section{ABSTRACT}

This article is based on a research made on private educational institutions, in São Paulo city, Brazil, which offers Social Work courses. To understand how research formation is taught in these places, is the aiming of this study. This is an important tool for social workers to get closer of reality. This study turned possible the meeting of legislation with the observation of institutional conditions and the work state of teaching staff, as well the students in this process.

KEYS WORDS: Research. Professional Formation. Social Work.

\footnotetext{
${ }^{1}$ Professora Adjunta da Universidade Federal de São Paulo - UNIFESP, Campus Baixada Santista, Departamento Saúde, Educação e Sociedade. E-mail: mluciagm@gmail.com
} 


\section{INTRODUÇÃO}

Este artigo resulta de reflexões expostas na tese de doutoramento (MIRA, 2012), resultantes do estudo que se aproximou em 2012, de instituições privadas que oferecem cursos de Serviço Social no município de São Paulo. O trabalho teve como problematização a formação de assistentes sociais para a pesquisa. Quatro anos depois, resulta também, das preocupações trazidas pelas atuais condições da oferta da educação no país que continuam impactando a formação profissional.

Desde os anos 1990, observava-se então, estimulada pelas ofertas do Estado brasileiro que se explicitavam tanto na legislação como nos incentivos fiscais a empresas de educação, a crescente expansão de cursos de Serviço Social privados. A tendência à privatização para a formação de assistentes sociais no Brasil e em especial no estado de São Paulo esteve colocada desde o nascimento da profissão no Brasil. Inicialmente, pela participação da Igreja Católica (1936), espraiando-se pela reforma universitária na ditadura militar (1968), e agudizando-se no final do século XX pelas opções neoliberais realizadas pelo Estado brasileiro. Evidenciava-se, enfim, a transmutação da lógica constitucional (BRASIL, 1988) de cidadania para a predominância da lógica de comércio, transformando a educação, de direito social, em produto de consumo.

Mas, por que especificamente o interesse pela pesquisa e pela dimensão investigativa da profissão? Ao considerar que o Serviço Social é uma profissão interventiva, que conta com profissionais capazes de leitura e sistematização de dados da realidade à luz de referenciais teóricos, na construção de propostas de intervenção que produzem efeitos nas relações sociais, a pesquisa em serviço torna-se um instrumento imprescindível para o trabalho profissional. Trata-se de uma profissão que deve formar para competências e habilidades específicas. Para Guerra,

[...] a investigação é inerente à natureza de grande parte das competências profissionais: compreender o significado social da profissão e de seu desenvolvimento sócio histórico, identificar as demandas presentes na sociedade, realizar pesquisas que subsidiem a formulação de políticas e ações profissionais, realizar visitas, perícias técnicas, laudos, informações e pareceres sobre a matéria de Serviço Social, identificar recursos. Essas competências referem-se diretamente ao ato de investigar, de modo que, de postura a ser

Serv. Soc. \& Saúde, Campinas, SP v. 14, n. 2 (20), p. 243-256, jul./dez. 2015 ISSN 1676-6806 
construída pela via da formação e capacitação profissional permanente (cuja importância é inquestionável), a investigação para o Serviço Social ganha o estatuto de elemento constitutivo da própria intervenção profissional (GUERRA, 2009, p. 712, grifos originais).

Naquele trabalho, portanto, entendia-se como relevante, a aproximação das condições de formação dos assistentes sociais, principalmente daquelas que possibilitariam processos de síntese através de experiências de pesquisa, reunindo conhecimentos teóricos e empíricos na graduação. As Diretrizes Curriculares objetivam a formação de intelectuais com capacidade de leitura e intervenção na realidade social. Assim também, a aproximação do tratamento da dimensão investigativa nas propostas formativas dos cursos, que deveria perpassar pelos diferentes componentes curriculares, tendo por objetivo, a formação de um perfil específico de profissional (MIRA, 2012).

Partia-se do pressuposto que, as condições conjunturais e as institucionais, que insurgiam no contexto poderiam estar condicionando a definição dos projetos pedagógicos, nem sempre em consonância com as Diretrizes Curriculares propostas pela Associação Brasileira de Ensino e Pesquisa - ABEPSS (1996), sobre a compreensão do lugar do ensino da pesquisa para o trabalho profissional e para a produção de conhecimento sobre a realidade social. Objetivava-se, portanto, compreender como os Cursos de Serviço Social construíam pedagogicamente e implementavam a formação em pesquisa na graduação.

Considerando que as 12 instituições de ensino do município de São Paulo, informadas à época ${ }^{2}$ no portal do Ministério da Educação e Cultura - MEC são privadas, constituiu-se uma amostra intencional com 5 instituições, entre as mais antigas e as mais recentes; entre cursos inseridos em universidades (3), em centros universitários (1) e escolas isoladas (1); com ensino presencial ou a distância. A aproximação da formação profissional através de coordenadores de curso, de professores de pesquisa e, de discentes que tiveram participação em iniciações científicas e/ou estavam elaborando o trabalho de conclusão de curso, (19 sujeitos) possibilitou a compreensão das condições institucionais, objetivas e subjetivas desse processo.

\footnotetext{
${ }^{2}$ Em uma rápida aproximação ao Portal do MEC é possível observar que na atualidade, cerca de 14 instituições oferecem cursos presenciais no município de São Paulo. MEC/EMEC. Acesso em 02/12/2016.

Serv. Soc. \& Saúde, Campinas, SP v.15, n. 2 (22), p. 243-256, jul./dez. 2016 ISSN 1676-6806
} 


\section{CONDIÇÕES, LIMITES E POSSIBILIDADES NA FORMAÇÃO EM PESQUISA}

A aproximação da formação profissional dos assistentes sociais objetivando compreender em que condições a pesquisa inseria-se nos projetos pedagógicos e nas grades curriculares dos cursos privados do município de São Paulo, possibilitou o encontro de fatores ligados às legislações que regulam a formação, às condições institucionais, às de trabalho de docentes, de coordenadores de curso e, as relacionadas aos discentes. É sobre esses fatores que a discussão a seguir se desenrola.

Um aspecto que incide diretamente na formação e já apontado por diferentes autores, (IAMAMOTO, 1999; ABREU, 2007) relaciona-se à existência, atualmente, de duas direções para a formação profissional. A primeira, construída coletivamente pelos assistentes sociais e apresentadas em 1996 (ABESS/CEDEPSS, 1997), contemporaneamente denominadas no meio profissional como as Diretrizes Curriculares da ABEPSS e a legal, publicada pelo Ministério da Educação e Cultura MEC (1996).

Para a formação em pesquisa, entre outras incidências, as propostas das duas Diretrizes contêm diferenças que impactam nas possibilidades do perfil profissional objetivado. As Diretrizes da ABEPSS propõem para o tratamento da matéria, como

[...] natureza, método e processo de construção do conhecimento: o debate teórico-metodológico. A elaboração e análise de indicadores socioeconômicos. A investigação como dimensão constitutiva do trabalho do Assistente Social e como subsídio para a produção do conhecimento sobre processos sociais e reconstrução do objeto da ação profissional (ABESS/CEDEPSS, 1997, p. 71).

As Diretrizes Curriculares do MEC objetivam, no entanto, competências diferenciadas, ao definir para a matéria pesquisa na formação de assistentes sociais, um conteúdo sensivelmente mais restrito. Propõem a formação voltada para:

[...] concepção, elaboração e realização de projetos de pesquisa. A pesquisa quantitativa e qualitativa e seus procedimentos. Leitura e interpretação de indicadores socioeconômicos. Estatística aplicada à pesquisa em Serviço Social (MEC/SESu citado por ABREU, 2007, p.121, destaques nossos). 
Observa-se a aptidão acadêmica proposta pelo MEC em contraposição da perspectiva da ABEPSS que objetiva para, além disso, um determinado perfil profissional, com competências e habilidades específicas. As instituições de ensino que se reportam, contudo, ao Ministério tendem a prontamente seguir as determinações deste.

As instituições que se aproximavam das Diretrizes da ABEPSS, mais do que apenas o cumprimento legal, contavam com a participação de docentes e coordenadores que as conheciam e trabalhavam para a construção da hegemonia do projeto profissional. Trata-se de um desafio que professores assumem individualmente, entre a venda de sua força de trabalho e a militância que busca resistência ao processo de aligeiramento dos cursos e desmoronamento da formação profissional que o mercado de ensino vem provocando.

Contudo, a expansão de Cursos de Serviço Social por instituições privadas possibilitou também, o alargamento do mercado de trabalho para assistentes sociais, recém-saídos dos cursos de pós-graduação. Ocorre, no entanto, que a pós-graduação nos níveis de mestrado e doutorado no Brasil, raramente tem a formação voltada para a docência, dedicando-se à formação de pesquisadores. Os docentes são praticamente autodidatas para o ensino superior.

Esta é uma séria dificuldade, que incide sobre a formação, não apenas no Serviço Social. Muito frequentemente, os pós-graduados ou os pós-graduandos adentram no mercado de trabalho, com o desconhecimento da didática e da pedagogia, necessárias nos processos educacionais.

O docente da graduação, além do conteúdo específico da área, e da competência para lidar com a produção do conhecimento, necessita de uma formação específica que lhe forneça instrumental para lidar com as relações de ensino-aprendizagem e com a cultura institucional na qual se insere. Tal formação mostra-se necessária até para propor mudanças, assegurar conquistas ou posicionarse em relação à desconstrução de princípios formativos humanos por interesses econômicos e financeiros, como ocorre na atual conjuntura.

Mas, nos cursos em instituições privadas também entre os docentes, em alguns casos, ocorre o desconhecimento de legislação específica da área que norteia a formação. Por vezes, professores desconhecem até mesmo o projeto político pedagógico Serv. Soc. \& Saúde, Campinas, SP v.15, n. 2 (22), p. 243-256, jul./dez. 2016 ISSN 1676-6806 
dos cursos em que trabalham. Para alguns, as instituições lhes disponibilizam na contratação, tão somente a ementa da disciplina pela qual, passam a ser responsável, o que geralmente lhes impossibilita, a conexão com as demais disciplinas.

Foi possível notar em algumas situações, o desconhecimento sobre os três núcleos de formação contidos nas Diretrizes Curriculares da ABEPSS: o dos fundamentos teórico metodológicos da vida social; o dos fundamentos da formação sócio histórica brasileira; o dos fundamentos do trabalho profissional. Tal condição poderia estar levando a abordagem na graduação, de conteúdos que não estabelecem nexos entre si, descaracterizando aquela proposta curricular pela concepção e perspectiva teórica adotada. Ou mesmo, por poder avançar na perspectiva marxista, mas sem garantias de superação do conservadorismo, e nesse sentido, estar produzindo uma formação em bases ecléticas, contrárias às bases teóricas necessárias para o trabalho profissional na perspectiva ainda hegemônica na profissão.

Em duas instituições, no entanto, observou-se um incentivo para a construção de um Núcleo Docente Estruturante - NDE, como recomenda o MEC, como estratégia de qualificar os cursos nos seus projetos pedagógicos.

As instituições impactavam na formação de outras formas, definindo em conformidade com o estabelecido na LDB/1996, em seis, sete ou oito semestres, o tempo de duração dos cursos. Isso pode estar contribuindo para um processo de aligeiramento da formação, sem as bases necessárias para o trabalho profissional.

As instituições poderiam ainda, estar interferindo diretamente no processo formativo, quando atuavam sobre a definição da grade curricular; não oferendo local de trabalho adequado e suficiente para professores e estudantes; na seleção, contratação e dispensa de professores; na falta de remuneração para as atividades fora da sala de aula, em especial, para as orientações de TCC; na definição do preço da hora/aula, a ser paga para os professores. Portanto, estudos, discussões coletivas entre docentes, planejamento e avaliação, quando ocorriam, com frequência poderiam ser caracterizados como trabalho não remunerado. Instituições privadas, muito frequentemente, remuneram apenas o trabalho em sala de aula e compõem o salário do professor por hora/aula. 
Entre os cinco cursos pesquisados, quatro limitavam a experiência dos alunos em pesquisa, apenas ao Trabalho de Conclusão de Curso - TCC. A experiência de iniciação científica foi observada em apenas uma das instituições, embora entre elas, três fossem universidades. A universidade se constitui como a única modalidade de ensino superior ${ }^{3}$ qualificada legalmente para o tripé: ensino, pesquisa e extensão.

Quanto aos estudantes, ocorria uma constatação pelos professores, no cotidiano do processo formativo, de que estariam ingressando com certa frequência, jovens e adultos com dificuldades reais para a leitura e interpretação de texto. Para a formação profissional essa condição precisa ser superada, demandando esforços do próprio estudante, dos professores e da instituição de ensino, na disponibilidade de meios que auxiliassem nesse processo.

Também se reiterou a observação de que, cada vez mais, o perfil do estudante descreve um trabalhador, que acessa a formação profissional, não só pela inconformidade com a realidade desigual e excludente, mas, também em busca da esperança de ascensão social. O fato de ser trabalhador, contudo, caracteriza-se como motivo para que faça um precário acúmulo de leituras e reflexões teóricas e aproximações empíricas. Portanto, a precarização da formação pode estar também relacionada à postura dos formandos.

Por outro lado, embora o estudante pudesse perceber a precarização, tanto do trabalho docente, como de sua própria formação, nessa aproximação dos cursos de Serviço Social, não foi possível notar naquele momento, movimentos coletivos desses sujeitos para reivindicar melhores condições de formação. Ocorriam, no entanto, algumas participações em instâncias organizativas de discentes nas instituições, como centros acadêmicos ou nas da própria profissão, como a Executiva Nacional de Estudantes de Serviço Social - ENESSO.

\footnotetext{
${ }^{3}$ A Lei de Diretrizes e Bases (BRASIL, 1996) isenta Escolas Isoladas e Centros Universitários da obrigatoriedade de produzir pesquisa e extensão. Entende-se que o lucro está mais próximo do ensino em cursos que não solicitam laboratórios ou infraestrutura dispendiosa. A pesquisa e a extensão, em contraposição, demandam custos.

Serv. Soc. \& Saúde, Campinas, SP v.15, n. 2 (22), p. 243-256, jul./dez. 2016 ISSN 1676-6806
} 


\section{NOVOS DESAFIOS À EDUCAÇÃO E À FORMAÇÃO PROFISSIONAL}

Na atualidade novas ameaças incidem sobre a educação, na universidade ou em instâncias anteriores a ela e, como direito social definido constitucionalmente. Tal situação trouxe como consequência a polarização da sociedade brasileira.

Do movimento “Escola Sem Partido” em curso no país, têm transitado no poder legislativo, diversos projetos de lei ${ }^{4}$ que pretendem alterar a Lei de Diretrizes e Bases. De autoria de integrantes que defendem os interesses do ensino privado e de movimentos conservadores evangélicos, tais projetos ambicionam retirar dos diferentes níveis de educação o princípio constitucional do pluralismo de ideias.

De iniciativa do governo federal a Medida Provisória (MP) 746/2016 encaminhada ao Congresso Nacional pretende a reestruturação do ensino médio. Embora estenda as horas de permanência dos alunos na escola, mantenha como obrigatório o ensino de português e matemática e, inclua o ensino de línguas (inglês e espanhol), retira do currículo disciplinas como a filosofia, a sociologia, o estudo das artes e a educação física. Propõe também a contratação de professores sem licenciatura, desde que apresentem "notório saber".

Também por iniciativa do governo federal a Proposta de Emenda Constitucional - PEC 55 em tramitação no Senado com o propósito de congelamento de gastos por 20 anos sobrevém diretamente em direitos sociais garantidos em 1988. A Educação e a Saúde, por exemplo, que têm estabelecidos um percentual da receita para o seu financiamento, deixarão de tê-los a partir de 2017. Ocorre que tais políticas embora incidam sobre o fundo público, constituem-se em investimentos necessários para populações atuais e futuras.

Em especial a Educação, foi o direito social reconhecido mais precocemente pelos trabalhadores como a via para a busca da igualdade, considerando que a mesma qualidade da educação para classes diversas possibilitaria oportunidades semelhantes. Verifica-se, portanto, pelas vias institucionais, iniciativas que atingem a classe

\footnotetext{
${ }^{4}$ PLS 193/2016 de autoria do senador Magno Malta, do PR do ES; PL 1411/2015 de autoria do deputado Rogério Marinho do PSDB do RN, e PL 867/2015 de autoria do deputado Izalci Lucas Ferreira do PSDB do DF.

Serv. Soc. \& Saúde, Campinas, SP v. 14, n. 2 (20), p. 243-256, jul./dez. 2015 ISSN 1676-6806
} 
trabalhadora brasileira nas suas condições e possibilidades de exercício da igualdade e liberdade.

A implementação de tais iniciativas, certamente trará impactos para o Ensino Fundamental e Médio, necessários e que precedem a formação de profissionais, como a dos assistentes sociais, que devem desenvolver criticidade para o trabalho em uma sociedade desigual como a brasileira.

Observa-se na atualidade, diferentemente do que há quatro anos, um movimento de jovens, tanto no ensino médio como nas universidades que se posicionam, se manifestam e ocupam escolas para expressar seu descontentamento com as investidas contra direitos sociais já conquistados. Trata-se de um exercício necessário de expressão na busca de assegurar políticas que na atualidade estão ameaçadas pelo rompimento do consenso entre os interesses de frações de classes em disputa.

\section{CONSIDERAÇÕES FINAIS}

Pela aproximação da formação de assistentes sociais foi possível a compreensão da ocorrência de uma séria disputa de interesses, relacionada aos propósitos formadores como já apontada por intelectuais de referência na área e pelos órgãos de representação da categoria profissional (ABREU, 2007).

A proposta das Diretrizes Curriculares da ABEPSS (ABESS/CEDEPSS, 1997) observa tanto os referenciais necessários à leitura e interpretação da realidade social, como ainda, para a construção de competências e habilidades para o trabalho profissional. Os referenciais, as competências e habilidades, explicitam a dimensão investigativa do trabalho profissional expresso tanto nas diretrizes produzidas pela profissão, como na Lei de Regulamentação profissional.

Entende-se, assim que a formação para a pesquisa excede as competências acadêmicas relacionadas à produção e comunicação de trabalhos científicos, embora deles não prescinda. Coloca-se, mais além, como instrumento de trabalho a ser operado competentemente. Sem a leitura sistematizada da realidade, à luz de referenciais teóricos e metodológicos que possibilitem a sua compreensão, e a produção de conhecimento, não é possível a elaboração de propostas de intervenção. Por outro lado, sem competência para a produção da pesquisa ou de leitura do conhecimento por ela produzido, opera-se a redução da ação profissional dos assistentes sociais ao lugar determinado na divisão do trabalho para os que fazem, contrapondo-se 
aos que pensam. As consequências, portanto, são consideráveis (MIRA, 2012, p. 326-327).

As Diretrizes Curriculares estabelecidas pelo MEC para o Serviço Social em 2001, portanto com força legal, reiteram, em relação à formação para à pesquisa, competências acadêmicas de leitura e comunicação científica e nesse sentido, reduzem as possibilidades profissionais.

É preciso observar a existência de ameaças concretas que se colocam à formação, na perspectiva da dimensão investigativa, seja pela definição curricular do Ministério; pelo processo de privatização do ensino; pelo aligeiramento da formação no encurtamento do número de semestres; pela direção que os coordenadores imprimem; ou pela postura de alguns professores; ou ainda pelo pensamento conservador que pode estar permeando a ação formativa.

Recentemente, observam-se ameaças aos diferentes níveis da educação no país que sofrem o assalto de projetos conservadores institucionais do poder executivo e do poder legislativo no nível federal, subordinados aos interesses privados de ensino, nacionais e internacionais.

Essas ameaças imprimem uma direção contrária à alcançada pelo Serviço Social no Brasil, na definição de seu projeto hegemônico.

As medidas implementadas pelo Ministério para delimitar padrões de formação e proceder a avaliação do ensino superior, parecem no momento, não surtir efeito no sentido de colocar limites nos interesses econômicos, que têm possibilitado a abertura do número expressivo de instituições privadas, preocupadas com a expansão de vagas para alunos pagantes.

Os sujeitos que se responsabilizam pela formação dos profissionais da área precisam ter clara a discussão colocada a respeito das propostas formativas. Mais que isso, é necessário posicionar-se em relação a elas. Além das ações construídas coletivamente pelos órgãos de representação da categoria, a partir do cotidiano, nas instituições em que se realiza a formação, desde os sujeitos que dela participam é que é possível construir estratégias de resistência. 
A formação dos formadores, porém é uma necessidade que se desdobra em direções diversas. A pós-graduação vem se dedicando à formação de pesquisadores, o que revela a importância no preparo de capacidades para a construção de conhecimento. Contudo, é preciso pensar em competências e habilidades docentes, sobre as quais, a pós-graduação tem responsabilidade e poderia contribuir de maneira relevante.

A pesquisa de 2006 sobre a implantação das Diretrizes Curriculares (ABEPSS, 2007) revelou que os referenciais teóricos e metodológicos que delineiam toda a proposta formativa construída pela profissão necessitam ser mais bem apropriados pelos docentes. A ABEPSS construiu uma proposta para formação de docentes visando o domínio dos referenciais teóricos necessário à formação dos assistentes sociais.

Trata-se de uma louvável iniciativa, a da “ABEPSS Itinerante”, que iniciou no primeiro semestre de 2012 e já se desdobrou em outros momentos. Contudo, a proposta alcança um número limitado de participantes, o que se contrapõe à demanda. Considerando que tanto os novos professores que adentram a carreira docente, como os que há tempos desempenham a função, precisam apropriar-se e aprofundar-se na direção do projeto profissional e dos referenciais que o embasam, haveria a necessidade de uma extensão das vagas.

Outra iniciativa da ABEPSS relaciona-se aos Grupos Temáticos de Pesquisa GTPs que contribuem para a comunicação e discussão de temas de estudo e para nortear a formação de núcleos de estudo e pesquisa nas diversas instituições formadoras. A frutificação dos GTPs se constitui numa possibilidade de resistência à precarização das condições de implantação do projeto de formação profissional.

Ocorre que as propostas da profissão para a formação, e, para a formação em pesquisa, são próprias de universidades. Ou seja, instituições que detém por determinação legal e por desempenho, as funções de produção e transmissão de conhecimento, bem como de compartilhamento do conhecimento produzido, em projetos de extensão fora dos muros da universidade. Trata-se de instituições que manejam os meios e recursos, detendo condições concretas de realização de pesquisa, estabelecendo núcleos de estudo e pesquisa, nos quais docentes e discentes empenhamse em estudos e ações acadêmicas ligadas à produção de conhecimento e extensão.

As determinações legais desencadeadas desde a LDB de 1996 acabaram por definir instituições de ensino superior que não têm obrigatoriedade de desenvolver Serv. Soc. \& Saúde, Campinas, SP v.15, n. 2 (22), p. 243-256, jul./dez. 2016 ISSN 1676-6806 
pesquisas ou projetos de extensão, considerando ainda que, mesmo as universidades privadas produzem muito pouco conhecimento.

Por outro lado, observou-se durante a pesquisa para a tese de doutoramento, a ameaça feita ao trabalho de conclusão de curso por coordenadores e professores. Ao avaliar as condições dos alunos egressos de escolas públicas, que revelavam muita dificuldade de acompanhamento da formação, esses formadores propunham o fim do trabalho resultante da única experiência de pesquisa do curso. Sugeriam para colocar no lugar da monografia resultante de pesquisa, a construção de um artigo sobre um tema pré-definido. Formadores assistentes sociais, nessa perspectiva, podem contribuir de maneira direta para a precarização da formação.

Relacionado aos alunos, surgiu o apontamento em todos os cursos estudados, sobre as condições de formação anterior à chegada ao ensino superior, como de muita precariedade. Observou-se, porém, em alguns relatos, o esforço empreendido por discentes que procuravam superar limites, construindo possibilidades de acesso ao conhecimento. Contudo, embora os estudantes entendessem a precarização das condições de ensino pelas quais passaram, não ocorria uma organização em relação ao seu enfrentamento, considerando-se ainda que alguns dos alunos entrevistados participavam de centros acadêmicos ou de organizações estudantis do Serviço Social. Ainda, a vida universitária e suas possibilidades eram claras para os que estavam matriculados na instituição que continha tais condições. Os demais tinham experiências acadêmicas, relacionadas ao ensino.

Constatou-se por fim, que embora a definição legal seja a assumida institucionalmente, que as determinações institucionais constituem-se em fortes desafios a serem enfrentados, que as condições materiais, realmente condicionem o trabalho de estudantes, professores e coordenadores, estes, conformam-se como importantes sujeitos no processo de formação na direção posta pela profissão dos assistentes sociais na atualidade, quando têm clareza sobre seus propósitos e empenham-se naquela direção. É também com eles que os esforços da profissão precisam desdobrar-se. 


\section{REFERÊNCIAS}

ABEPSS. Temporalis. Diretrizes Curriculares do Curso de Serviço Social: sobre o processo de implementação. $n^{0}$ 14. São Luís: ABEPSS, jul./dez./ 2007. 252 p.

ABESS/CEDEPSS. Diretrizes Gerais para o Curso de Serviço Social (Com base no currículo mínimo aprovado em Assembleia Geral Extraordinária de 8 de novembro de 1996) Cadernos ABESS $n^{0}$ 7. Formação Profissional: trajetórias e desafios. Ed. Especial. São Paulo: Cortez, 1997, p. 58-76.

ABREU, M. M. Pesquisa em Serviço Social: tendências na implementação das Diretrizes Curriculares. Temporalis, nº 14. São Luís: ABEPSS, jul./dez./ 2007, p. 119148.

BRASIL. Constituição (1988). Constituição Federativa do Brasil de 1988. Disponível em: http://www.planalto.gov.br/ccivil_03/Constituicao/Constituicao.htm. Acesso em 02/jan./2012 e em 01/12/2016.

BRASIL. Lei 9.394, de 20 de dezembro de 1996. Estabelece as Lei de Diretrizes e Bases da Educação Nacional. In SAVIANI, D. A nova Lei da educação: LDB, trajetória, limites e perspectivas. 10ª ed. Campinas-SP. Autores Associados, 2006.

Disponível também em: http://www.planalto.gov.br/ccivil_03/Leis/L9394.htm. Acesso em 02/jan./2012 e em 25/11/2016.

GUERRA, I. A dimensão investigativa no exercício profissional. In: CFESS/ABEPSS. Serviço Social: Direitos Sociais e Competências Profissionais. Brasília: CFESS/ABEPSS, 2009, p. 701-718.

IAMAMOTO, M.V. O Serviço Social na Contemporaneidade: trabalho e formação profissional. $2^{\text {a }}$ ed. S. Paulo: Cortez, 1999.

MIRA, M. L. G. A dimensão investigativa e a pesquisa em Serviço Social: condicionantes da formação em instituições de ensino superior no município de São Paulo. Tese de doutoramento, Programa de Estudos Pós-Graduados em Serviço Social, Pontifícia Universidade Católica de São Paulo - PUC-SP. São Paulo, 2012 
Serv. Soc. \& Saúde, Campinas, SP v. 14, n. 2 (20), p. 243-256, jul./dez. 2015 ISSN 1676-6806 